\title{
A sectionalized-dual-band method for the selection of ground motion record sets
}

\author{
Hongmei Hou \\ Department of Civil Engineering, Qingdao University of Technology, Qingdao, 266033, China \\ houhm@qut.edu.cn
}

Submitted: $19 / 09 / 2018$

Revised: $06 / 12 / 2020$

Accepted: $13 / 12 / 2020$

\begin{abstract}
It is of great importance to select appropriate ground motion records for time-history dynamic analysis of structures. The consistency between record response spectral shape and seismic design response spectral shape is the basic principle for records selection. A sectionalized-dual-band (SDB) method considering influence of higher modes was proposed to select ground motion records according to the seismic fortification intensity requirements and the site characteristic. Furthermore, the newly proposed method has been employed to construct record sets within the whole response spectrum period. As compared with other traditional methods, the records obtained from the SDB method are more effective in predicting base shear derived from time-history dynamic analysis. When the period of a structure is determined, the records in the matched period range of the records set can be directly used to conduct time-history dynamic analysis. This method can avoid tedious work for reselecting ground motion records for different structures in the same seismic design intensity and site conditions.
\end{abstract}

Keywords: Ground motion records; Response spectrum; Higher modes; Record sets.

\section{INTRODUCTION}

The elastic-plastic time-history dynamic analysis of structures has become a major numerical method used to evaluate the seismic performance of structures, as the performance-based seismic design methodology develops. The input of ground motion records introduces uncertainty in structural response obtained from time-history analysis of structural systems. Different records have had a huge impact on time-history analysis, with results varying greatly. Therefore, selection of appropriate ground motion records is the basis and the key to successful structure seismic design.

The response spectrum-based method of selecting ground motion records is the main selection method for timehistory analysis. For the response spectrum-based method, the spectra selected both for ground motions and design specification should be as close as possible to control the spectral characteristics of selected records. ATC 63 (2009) and ASCE 7-16 (2017) base the selection on both earthquake-related parameters (magnitude, epicentral distance, type of seismic fault, etc.) and spectral compatibility between records and the design spectrum. Stewart et al. (2002) and Bommer \& Acevedo (2004) argued that the earthquake's environmental setting should be taken into account and that magnitude was the primary control factor, and then spectrum-based selection was used to refine the preselection. Yang et al. (2000) put forth a dual-band (DB) method based on the platform segment of design response spectrum and the basic period of structures. Katsanos et al. (2010) reviewed previous ground motion selection methods and did the optimization analysis to determine the optimal proportion coefficient by solving the minimum difference between SRSS spectrum and the design response spectrum. Baker (2010) proposed the conditional mean spectrum and used it as the tool for records selection. Bradley (2010) used the conditional mean spectrum and the generalized conditional 
intensity to select records, which considered the variability in the target spectrum. Hashash et al. (2015) constructed the conditional mean spectrum and selected records based on it, which proved the rationality of calculated results. Carlson et al. (2016) proposed the records selection method of multifrequency weighted matching, which is based on the acceleration response spectrum and considered the influence of high-order mode. Ji et al. (2017) established the records selection database according to the design spectrum by using the spectrum matching results to optimize the weight function. Lu et al. (2018) treated the uniform hazard spectrum, the scenario spectrum, and the conditional mean spectrum as target spectrum, to select ground motion records. And the new edition of the ASCE/SEI 7-16 (2017) has proposed using the conditional mean spectrum.

The response spectrum-based method can reduce the dispersion of structural performance. The records selection method provided by Chinese seismic design code for buildings (2016) not only considers the uniformity of earthquake conditions and seismic effect coefficient curve in statistical significance, but also considers the base shear of structures, which considers design categories, site conditions, and period of buildings. Integrating the earthquake conditions-based and the response spectrum-based, a sectionalized-dual-band (SDB) method for ground motion records selection was proposed in this paper, which was used to construct sets of ground motion records. In addition, the records in the alternative sets were used for dynamic analysis of structures to verify the feasibility and superiority of the proposed method.

\section{THE INDEX TO QUANTIFY THE SPECTRAL MATCHING}

The dual-band (DB) method, proposed by Yang et al. (2000), is representative of the response spectrum-based methods for ground motion records selection, which directly compares the record spectrum with the design response spectrum to control spectral characteristics of selected records; namely, the record spectrum and the design spectrum must be as close as possible. This method requires the relative difference between average values of records spectrum and design spectrum to be no more than $10 \%$ within the platform range $\left[0.1, T_{g}\right]$ and the period range $\left[T_{1}-\Delta T_{1}, T_{1}+\Delta T_{2}\right]$, after the scaling in accordance with the design code in China. $T_{\mathrm{g}}$ is the design characteristic period of ground motion, which is often determined by source-related mechanisms (especially in near-source conditions) and site (subsoil, topography) conditions. $T_{1}$ is the basic period of structures, and $\Delta \mathrm{T}_{1}$ and $\Delta \mathrm{T}_{2}$ are period control ranges. Considering the period elongation of structures when structures suffer from earthquake, $\Delta \mathrm{T}_{1}$ is proposed to be $0.2 \mathrm{~s}$, and $\Delta \mathrm{T}_{2}$ is $0.5 \mathrm{~s}$ (Yang et al., 2000).

The relative difference $\delta\left(T_{m}, T_{n}\right)$ is used as the difference between average values of record spectrum and design spectrum from $T_{m}$ to $T_{n}$. The value of $\delta\left(T_{n}, T_{m}\right)$ is expressed as

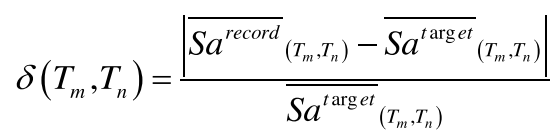

where $\overline{\mathrm{Sa}^{\text {target }}}{ }_{\left(T_{m}, T_{n}\right)}$ and $\overline{\mathrm{Sa}^{\text {record }}}{ }_{\left(T_{m}, T_{n}\right)}$ are average spectrum values of the design spectrum and the record spectrum in each controlled period range, respectively, and $T_{m}$ and $T_{n}$ are spectrum periods.

The Pacific Earthquake Engineering Center (PEER) developed a ground motion selection system based on the database of ground motion records (Haselton, 2009 \& CGS-SMIP, 2010). The basic principle of the system to select records is that the shape of record spectrum should match the target spectrum shape in the designated period range. And the period range should be determined according to structure characteristics. The system measures the matching degree between the record spectrum and the target spectrum according to the principle of minimum mean squared error (MSE), which measures the average of the squares of errors (Wang et al., 2015). The value of MSE is expressed as

$$
M S E=\frac{1}{n} \sum_{i=1}^{n}\left[\theta\left(T_{i}\right)-\bar{\theta}\left(T_{i}\right)\right]^{2}
$$


where

$$
\bar{\theta}\left(T_{i}\right)=\frac{1}{n} \sum_{i=1}^{n} \theta\left(T_{i}\right)
$$

And

$$
\theta\left(T_{i}\right)=\ln \left[\operatorname{Sa}^{\text {target }}\left(T_{i}\right) / S a^{\text {record }}\left(T_{i}\right)\right]
$$

where $S a^{\text {target }}\left(T_{i}\right)$ and $S a^{\text {record }}\left(T_{i}\right)$ are spectrum values of target spectrum and record spectrum of ground motion records in each $T_{i}$ (periodic point), respectively.

Both Equation (1) and Equation (2) represent the closing degree of record spectrum and design spectrum, and the smaller value shows the closer degree. In addition, the two equations were compared by Hou and Liu (2019). The comparison and analysis show that the ground motion records with minimum $\delta\left(T_{n} T_{m}\right)$ and with minimum MSE were different in each period range, even though the assessment principle was consistent with the design spectrum. However, the matching between the spectra of records with minimum MSE and the design spectrum had a tendency toward instability in all period ranges, while the index $\delta\left(T_{n} T_{m}\right)$ was more reliable than the index MSE when it came to controlling closeness between record spectrum and design spectrum. Therefore, in the new method proposed below, the index $\delta\left(T_{n} T_{m}\right)$ was used to control the matching of record spectrum and design spectrum.

\section{THE SECTIONALIZED-DUAL-BAND METHOD}

The new edition of ASCE/SEI 7 (2016) bases the record selection on both earthquake-related parameters (earthquake magnitude, epicentral distance, type of seismic fault, etc.) and spectral compatibility between record spectrum and design spectrum. Furthermore, records are selected in two steps, including 1) preliminary selection based on casual parameters; 2) final selection based on spectral shape, limiting the number of records from each single event, and limiting the scale factor. In Chinese code for seismic design of buildings (GB50011-2016 version, 2016), the seismic precautionary intensity, basic design accelerations of ground motion, and design earthquake groups are offered, which are the seismic bases of a region. And the maximum earthquake acceleration in the Chinese seismic design code is the scale factor to control the maximum acceleration value of records.

As different structures have different basic periods, ground motion records should be reselected in the DB method proposed by Yang et al. (2000) when the structure changes, and its calculation process is complicated. In addition, the alternative sets by the DB method proposed by Yang et al. (2000) fail to set up due to their dependence on the basic period of structure. What is more, the DB method does not take care of the higher modes, which are important for tall buildings. The influence of higher modes on the tall buildings cannot be fully reflected, as the second or third vibration period does not fall into the platform stage of the response spectrum. Thus, a method is needed to consider the influence of higher modes to select ground motion records.

The dynamic differential equation of multidegree freedom system can be expressed as

$$
[M]\{\ddot{u}\}+[C]\{\dot{u}\}+[K]\{u\}=-[M] I \ddot{u}_{g}
$$

where $[M]$ is the mass matrix of the structure, $[C]$ is the damping matrix, $[K]$ is the stiffness matrix, $[\ddot{u}]$ is the relative acceleration vector, $[\dot{u}]$ is the relative velocity vector, $[u]$ is the relative displacement vector, $I$ is the unit vector, and $\ddot{u}_{g}$ is the acceleration of ground motion.

Both sides of the above equation are multiplied by $\left\{\varphi_{i}\right\}^{T}$. According to the multidegree freedom system, the mass matrix and the stiffness matrix meet orthogonally. And assume that the mode of vibration with respect to the damping matrix is also orthogonal. Then, $\mathrm{N}$ modes of vibration after decoupling can be obtained, among which the ith mode of vibration equation is 
$\ddot{q}_{i}+2 \omega_{i} s_{i} \dot{q}_{i}+\omega_{i}^{2} q_{i}=-\Gamma_{i} R \ddot{u}_{g}$

where $\omega_{i}$ and $s_{i}$ are frequency and damping ratio of the ith mode, respectively; $\Gamma_{i}$ is the ith order modal participation factor.

As the sum of all modes base shear is numerically equal to the total mass of the structure, under the action of unit acceleration, the ith modal participating mass ratio $\eta_{i}$ can be equivalent to the ratio of the ith mode base shear to the total structure base shear:

$$
\eta_{i}=M_{i}^{*} / \sum_{i=1}^{N} M_{i}^{*}
$$

where $M_{i}^{*}$ is the ith mode participation mass, and $M_{i}^{*}=\Gamma_{i}^{2} M_{i}$.

The modal participating mass ratio $\eta_{i}$ is a reasonable index to measure the contribution of structural vibration mode to the overall vibration response of the structure, which represents the contribution of the ith mode to the seismic response of the structure (Zhou \& Tang, 2014). Thus, the modal participating mass ratio $\eta_{i}$ was used as the weight coefficient to consider the higher modes.

In that way, a records selection considering the higher modes of structures was proposed, called the sectionalizeddual-band (SDB) method. It requires the relative difference between average values of records spectrum and design spectrum to be no more than $15 \%$ within the platform range $\left[0.1, T_{g}\right]$ and the period range $\left[T_{m}, T_{n}\right]$. And the period range is determined by the weight coefficient of multiple frequency bands composed of several vibration periods of the structures. The calculation formula is as follows:

$$
\left\{\begin{array}{l}
\delta\left(0.1, T_{g}\right)=\frac{\left|{\overline{S a^{\text {record }}}}_{\left(0.1, T_{g}\right)}-\overline{S a^{t \arg e t}}\left(0.1, T_{g}\right)\right|}{\overline{S a^{t \arg e t}}\left(0.1, T_{g}\right)} \\
\delta\left(T_{m}, T_{n}\right)=\frac{\sum_{i=1}^{n} \eta_{i}\left|\overline{S a^{\text {record }}}\left(T_{m}, T_{n}\right)-S a_{\left(T_{m}, T_{n}\right)}^{t_{\arg e t}}\right| / \overline{S a^{t \arg e t}}\left(T_{m}, T_{n}\right)}{\sum_{i=1}^{n} \eta_{i}}
\end{array}\right.
$$

The SDB method was proposed to tide over those problems, which were characterized by four requirements: 1) taking earthquake environmental elements influences into account, such as site condition, source magnitude, and site-source distance; 2) studying the impact of site characteristic period $\left(T_{g}\right)$ that refers to the influence of the platform range of the response spectrum; 3) cutting the whole spectral period into different ranges and keeping the consistency between record spectrum and design spectrum that will reduce the dispersion and increase the accuracy; and 4) maintaining independence of structure basic period, so that records reselection can be omitted when the basic period varies, and the record sets can be established. The steps of the SDB method are as follows:

(1) Select ground motion records from the PEER system complying with station and earthquake information.

Selection begins by inputting the design response spectrum and setting limited conditions of ground motion. The limited conditions of ground motion mainly encompass magnitude, fault type, rupture distance (R-rup), distance Joyner and Boore (R-JB), effective duration (D5-95), average shear wave velocity in the top 30m of soil ( $\left.\mathrm{V}_{\mathrm{s} 30}\right)$, and scaling method.

(2) Select the records by step (1) using response spectrum control.

Scale the records by the peak ground acceleration specified in the Chinese code for seismic design of buildings (GB50011-2016 version, 2016). Obtain the acceleration response spectrum of records after scaling. 
From the perspective of universality, the periods of structures are uncertain for the time being. The site characteristic period $T_{g}$ is used as the demarcation point to divide spectrum into one platform band [0.1 $\left.\mathrm{s}, T_{g}\right]$ and the basic period $T_{1}$ multiple period bands including $\left[T_{g}, T_{i}\right),\left[T_{i}, T_{i+1}\right),\left[T_{i+1}, T_{i+2}\right),\left[T_{i+2}, T_{i+3}\right),\left[T_{i+3}, T_{i+4}\right) \ldots$, where $T_{i}, T_{i+1}, T_{i+2}, T_{i+3}$ and $T_{i+4}$ are different points of the period. When selecting records, the platform range and one of the period ranges are controlled simultaneously. It is assuming that the $\eta_{i}$ decreases by $50 \%$, since the $\eta_{i}$ is unknown. And the structure periods of higher modes are also assumed to decrease by $50 \%$.

(3) Use Equation (8) to calculate the $\delta\left(T_{n} T_{m}\right)$ in all controlled ranges. And then, the ground motion records with $\delta\left(T_{n} T_{m}\right) \leq 10 \%$ are selected.

\section{CONSTRUCTION OF GROUND MOTION RECORDS SET}

\section{The Method of Set Construction}

The records in existing structure design software or structure finite element analysis software lack matching in earthquake environment and structural form according to the Chinese seismic design code requirements, and they are only selected from several typical earthquakes that have occurred in the past. Thus, a complicated process is followed to select the appropriate records in application. Therefore, the SDB method was put forth to select records, and record sets were constructed. The record sets with various seismic fortification intensities and site characteristic periods compose a record database. Records can be directly selected from the database once the structure basic period is determined. The establishment and use of record database steps are shown in Figure 1. That is only a way to select ground motion records and to build a record set provided, so the record set constructed by the SDB method can be based on the records selected not only from the PEER system, but also from other databases of ground motion records (such as the databases of Japan, China, etc.).

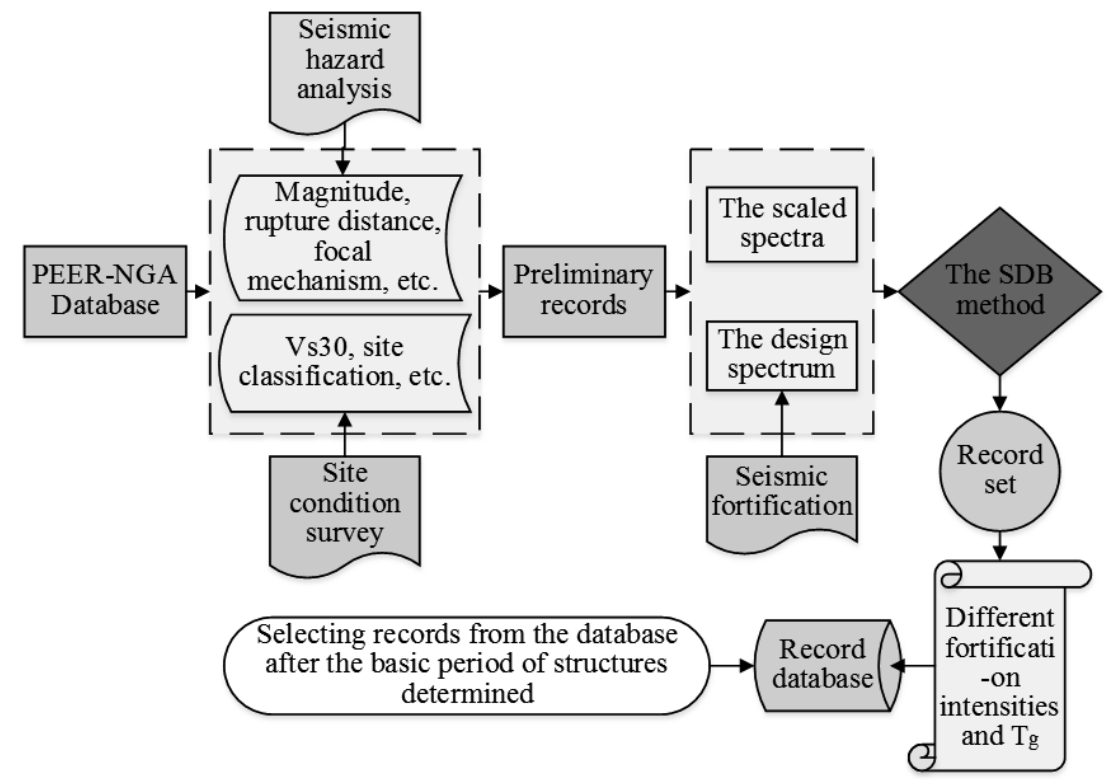

Figure 1. Construction and application steps of the record database.

\section{An Example of Construction in the Areas of Chinese Seismic Fortification Intensity 7}

According to the jurisdiction approved by China, the seismic fortification intensity can be obtained by using the basic seismic intensity of Chinese seismic parameter zoning map. An example of seismic fortification intensity 7 , site classification II, and design earthquake group III was taken to select ground motion records and construct record set, which considered 5 modes of structures. 
Initially, one hundred ground motion records were selected from the PEER. Then, these records were controlled according to the SDB method. The results of selected records are shown in Table 1. The comparisons between record spectra selected by SDB method and design spectrum are shown in Figure 2, which present good consistency in the platform range and the corresponding period ranges.

Table 1. The record set constructed by the SDB method.

\begin{tabular}{|c|c|c|c|c|c|c|c|c|c|c|}
\hline \multicolumn{3}{|c|}{$\delta$} & \multirow[b]{2}{*}{ Earthquake name } & \multirow{2}{*}{$\begin{array}{l}\text { Record } \\
\text { number }\end{array}$} & \multirow[b]{2}{*}{ Year } & \multirow[b]{2}{*}{$\mathbf{M}_{\mathbf{L}}$} & \multirow{2}{*}{$\begin{array}{c}\text { Effective } \\
\text { duration(s) }\end{array}$} & \multirow{2}{*}{$\begin{array}{l}\text { R-rup } \\
\text { (km) }\end{array}$} & \multirow{2}{*}{$\begin{array}{l}V_{\mathrm{s} 30} \\
(\mathbf{m} / \mathbf{s})\end{array}$} & \multirow{2}{*}{$\begin{array}{c}\text { Lowest } \\
\text { Frequency } \\
(\mathbf{H z})\end{array}$} \\
\hline \multicolumn{2}{|c|}{ Periods band } & $\begin{array}{c}\text { Platform } \\
\text { band }\end{array}$ & & & & & & & & \\
\hline \multirow{6}{*}{$0.45 \mathrm{~s}, 1 \mathrm{~s}$} & 0.061 & 0.063 & Loma Prieta & 746 & 1989 & 6.93 & 17.8 & 53.6 & 391.01 & 0.096 \\
\hline & 0.051 & 0.069 & Chi-Chi_Taiwan & 1380 & 1999 & 7.62 & 32.5 & 30.85 & 497.22 & 0.05 \\
\hline & 0.032 & 0.073 & Landers & 3752 & 1992 & 7.28 & 27.3 & 45.34 & 436.14 & 0.125 \\
\hline & 0.089 & 0.074 & Northridge-01 & 945 & 1994 & 6.69 & 15.5 & 38 & 349.6 & 0.2 \\
\hline & 0.052 & 0.087 & Iwate_Japan & 5808 & 2008 & 6.9 & 19.2 & 39.06 & 317.41 & 0.2 \\
\hline & 0.098 & 0.094 & Chi-Chi_Taiwan & 1290 & 1999 & 7.62 & 26.6 & 58.05 & 543.06 & 0.0625 \\
\hline \multirow{7}{*}{$1 \mathrm{~s}, 2 \mathrm{~s}$} & 0.073 & 0.015 & Chi-Chi_Taiwan & 1190 & 1999 & 7.62 & 39.1 & 50.53 & 497.53 & 0.0375 \\
\hline & 0.076 & 0.056 & Niigata_Japan & 4183 & 2004 & 6.63 & 46 & 55.94 & 303.73 & 0.0375 \\
\hline & 0.010 & 0.067 & Chi-Chi_Taiwan & 1274 & 1999 & 7.62 & 20.5 & 53.79 & 494.32 & 0.1875 \\
\hline & 0.041 & 0.074 & Northridge-01 & 945 & 1994 & 6.69 & 15.5 & 38 & 349.6 & 0.2 \\
\hline & 0.072 & 0.077 & Darfield_New Zealand & 6896 & 2010 & 7 & 27.9 & 32.91 & 280.26 & 0.125 \\
\hline & 0.075 & 0.080 & Chi-Chi_Taiwan & 1276 & 1999 & 7.62 & 17 & 51.62 & 437.8 & 0.0375 \\
\hline & 0.043 & 0.087 & Iwate_Japan & 5808 & 2008 & 6.9 & 19.2 & 39.06 & 317.41 & 0.2 \\
\hline \multirow{5}{*}{$2 \mathrm{~s}, 3 \mathrm{~s}$} & 0.038 & 0.007 & Iwate_Japan & 5493 & 2008 & 6.9 & 45.9 & 48.14 & 288.82 & 0.0375 \\
\hline & 0.061 & 0.024 & Darfield_New Zealand & 6988 & 2010 & 7 & 26.2 & 26.93 & 344.02 & 0.175 \\
\hline & 0.031 & 0.059 & Irpinia_Italy-01 & 294 & 1980 & 6.9 & 22.9 & 53.16 & 496.46 & 0.15 \\
\hline & 0.017 & 0.074 & Northridge-01 & 945 & 1994 & 6.69 & 15.5 & 38 & 349.6 & 0.2 \\
\hline & 0.076 & 0.077 & Darfield_New Zealand & 6896 & 2010 & 7 & 27.9 & 32.91 & 280.26 & 0.125 \\
\hline \multirow{5}{*}{$3 \mathrm{~s}, 4 \mathrm{~s}$} & 0.072 & 0.013 & Hector Mine & 1813 & 1999 & 7.13 & 24.4 & 53.21 & 396.41 & 0 \\
\hline & 0.054 & 0.063 & Loma Prieta & 746 & 1989 & 6.93 & 17.8 & 53.6 & 391.01 & 0.096 \\
\hline & 0.034 & 0.071 & Chi-Chi_Taiwan & 1291 & 1999 & 7.62 & 31.4 & 58.22 & 534.41 & 0.025 \\
\hline & 0.061 & 0.075 & Chi-Chi_Taiwan & 1581 & 1999 & 7.62 & 28.5 & 56.3 & 510.62 & 0.0375 \\
\hline & 0.099 & 0.077 & Darfield_New Zealand & 6896 & 2010 & 7 & 27.9 & 32.91 & 280.26 & 0.125 \\
\hline \multirow{2}{*}{$4 \mathrm{~s}, 5 \mathrm{~s}$} & 0.019 & 0.024 & Darfield_New Zealand & 6988 & 2010 & 7 & 26.2 & 26.93 & 344.02 & 0.175 \\
\hline & 0.10 & 0.077 & Darfield_New Zealand & 6896 & 2010 & 7 & 27.9 & 32.91 & 280.26 & 0.125 \\
\hline \multirow{4}{*}[5\mathrm{s},6\mathrm{s}]{} & 0.023 & 0.024 & Darfield_New Zealand & 6988 & 2010 & 7 & 26.2 & 26.93 & 344.02 & 0.175 \\
\hline & 0.069 & 0.064 & Iwate_Japan & 5760 & 2008 & 6.9 & 50.6 & 36.73 & 410.57 & 0.0375 \\
\hline & 0.052 & 0.077 & Darfield_New Zealand & 6896 & 2010 & 7 & 27.9 & 32.91 & 280.26 & 0.125 \\
\hline & 0.068 & 0.085 & Chi-Chi_Taiwan & 1299 & 1999 & 7.62 & 36.1 & 43.01 & 452.83 & 0.075 \\
\hline
\end{tabular}




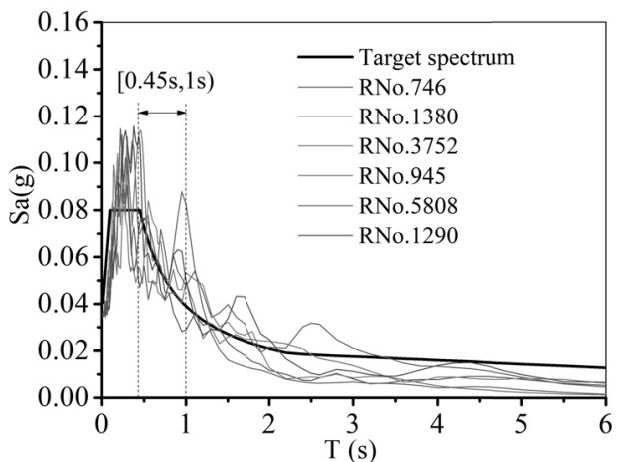

(a) $[0.45 \mathrm{~s}, 1 \mathrm{~s})$ Period range

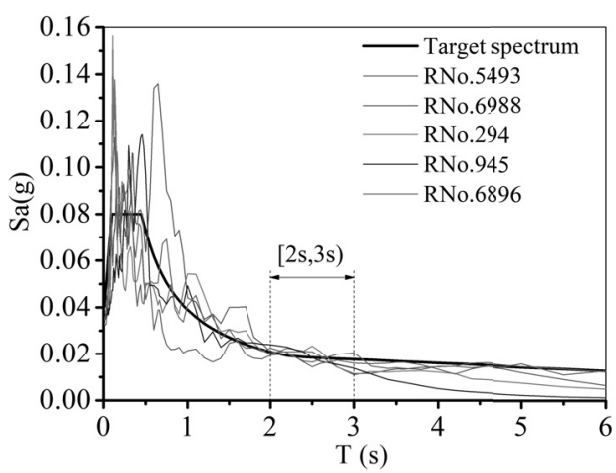

(c) $[2 \mathrm{~s}, 3 \mathrm{~s})$ Period range

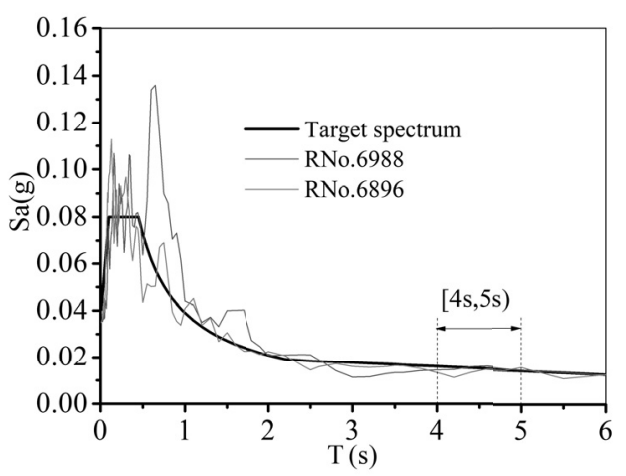

(e) $[4 \mathrm{~s}, 5 \mathrm{~s})$ Period range

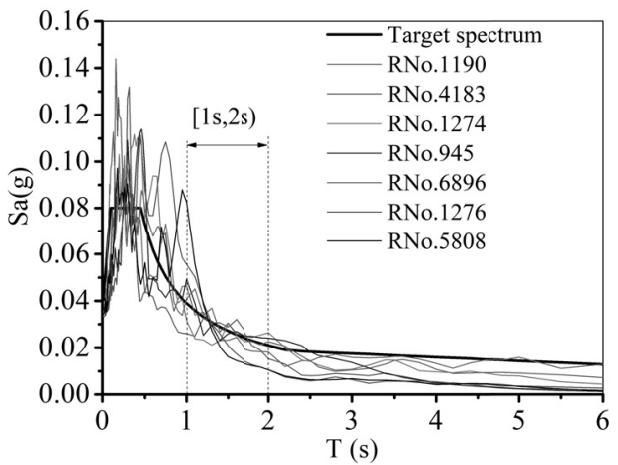

(b) $[1 \mathrm{~s}, 2 \mathrm{~s})$ Period range

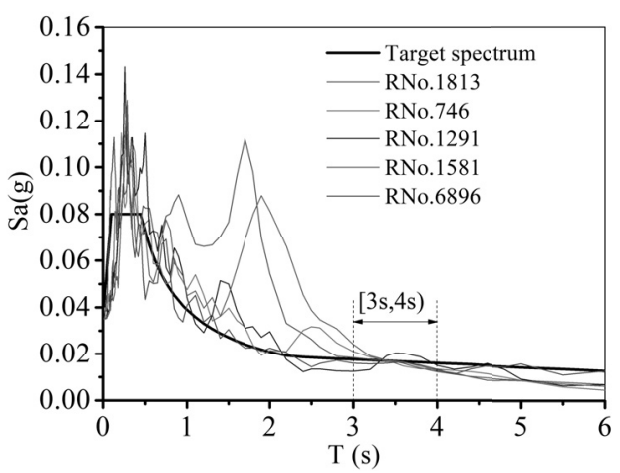

(d) $[3 \mathrm{~s}, 4 \mathrm{~s})$ Period range

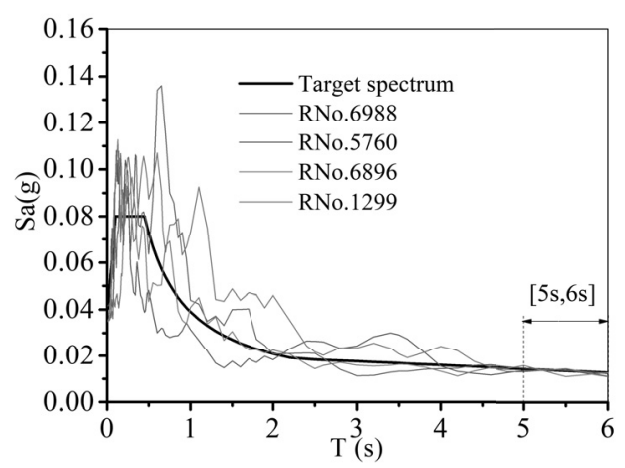

(f) $[5 s, 6 s]$ Period range

Figure 2. Comparisons between the record spectra selected by SDB method and the design spectrum.

The records in Table 1 constituted the set grouped by seismic fortification intensity 7, site classification II, and design earthquake group III. The basic acceleration of ground motion is $0.1 \mathrm{~g}$, which is obtained from the relation between seismic fortification intensity and the basic acceleration values of ground motion (GB50011-2016 version, 2016). If the basic period of the structure is decided, the records within the period range, where the structure basic period stays in, can be directly chosen from the set. Considering that structures practically enter into the plastic state under the strong earthquake, the structural stiffness degrades, and the basic period of structure is elongated. When a structure's basic period is just the division value of period ranges, the records in the period range lagging behind the division value are selected. And when the structure's basic period is in the platform range $\left[0.1 \mathrm{~s}, T_{g}\right]$, the records in the range of $\left[0.1 \mathrm{~s}, T_{g}\right]+\left[T_{g}, 1 \mathrm{~s}\right)$ are selected. 
For the record set shown in Table 1, there are only 3 7 records in each period range, but the records characterize the uncertainty of the 100 records, as they are selected from the 100 records; thus, structures belong to every period range choosing records within the set that is reasonable and feasible. Of course, if the preselection number of the records from the PEER increases, the number of records constituting the set will increase.

\section{EVALUATION OF THE GROUND MOTION RECORDS SET}

Four engineering structures were regarded as study objects to demonstrate the effectiveness of the records in the set. SAP2000 (a software of finite element analysis) was used to establish the structural models to do time-history dynamic analysis and obtain the base shear. The seismic fortification intensity was 7 , the site classification was II, the design earthquake group was III, and the maximum earthquake acceleration was $0.35 \mathrm{~m} / \mathrm{s}^{2}$ (standard value of frequent seismic) (GB50011-2016 version, 2016). The concrete strength of the two frame structures was that of C40, and the concrete strength of the two frame-shear structures was between C30 and C55. The strength of the stirrup was that of HRB335, and the strength of the other longitudinal bars was that of HRB400. In the models, the $3 \mathrm{~d}$ frame element was used to simulate beams and columns, the membrane element was used to simulate the floor slab, and the load between beams was $6.0 \mathrm{kN} / \mathrm{m}^{2}$. The structural damping adopted the classical Rayleigh damping, and the ratio was 0.05 . The default hinge properties in SAP2000 were specified for the frame element: the bending hinge in the spindle direction (M3) was specified at both ends of the frame beam, and the coupling hinge (p-m2-m3) was specified at the bottom of the frame column to allow the interaction between the axial force and bending moment. The key parameters of the four structures are shown in Table 2.

Table 2. Parameters of engineering structures.

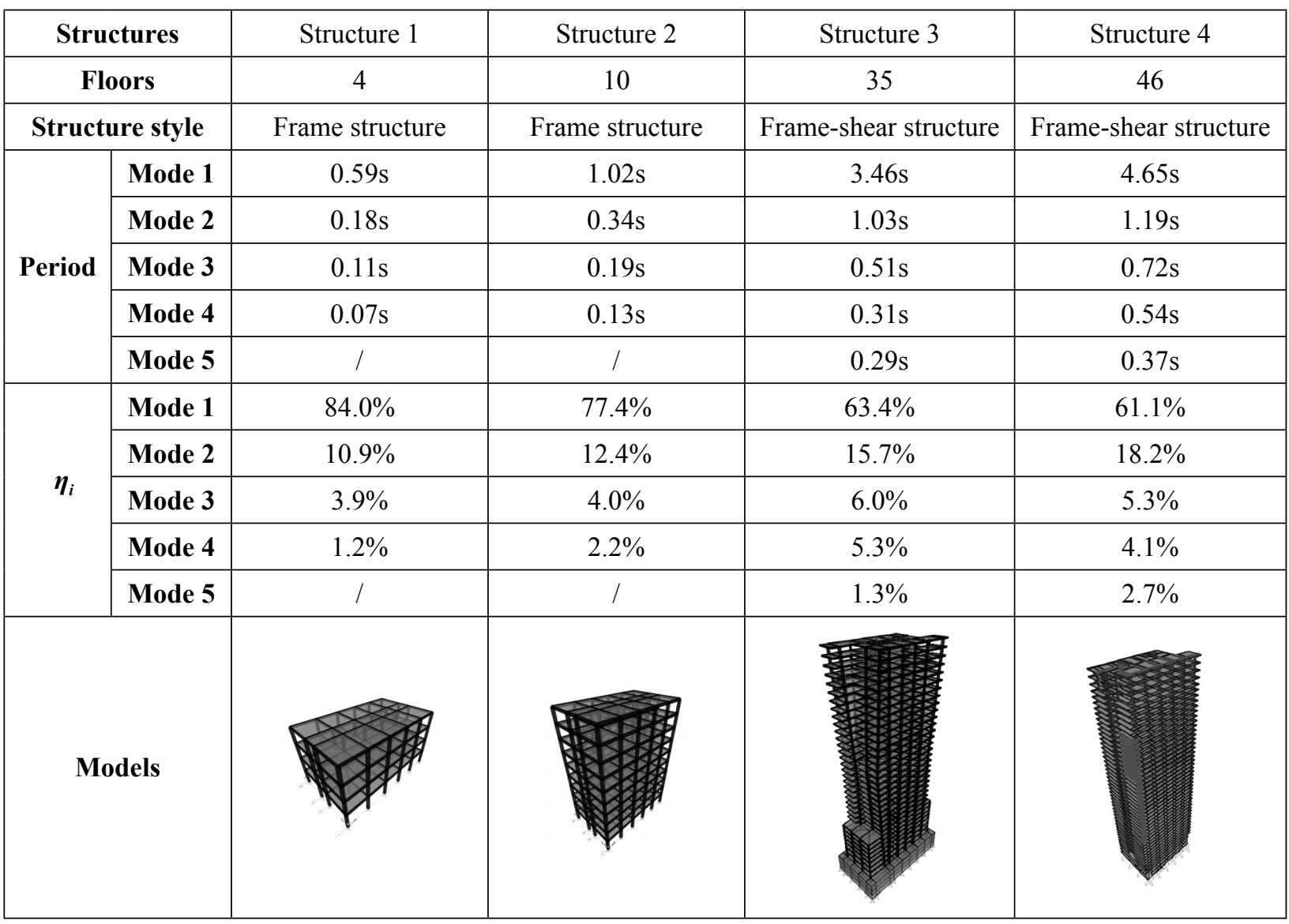


According to the Chinese code for seismic design of buildings (GB50011-2016 version, 2016), the evaluating principle of ground motion records is that the base shear obtained from the elastic time-history analysis with one record should be over $65 \%$ of the base shear obtained from the response spectrum modal analysis, and the average base shear obtained from the elastic time-history analysis with multiple records should be over $80 \%$ of the base shear obtained from the response spectrum modal analysis.

The appropriate records can be selected from the set (Table 1) according to the basic period of every structures. The comparisons of base shear results between elastic time-history dynamic analysis and response spectrum modal analysis are shown in Table 3. To draw a comparison of records selected from the set, one hundred records were selected randomly from the PEER without any selection condition and then selected through the DB method. Then, time-history dynamic analyses were done with the selected records. The results are shown also in Table 3 . The base shear by response spectrum modal analysis is $\mathrm{V}_{\mathrm{s}}$, and the base shear by time-history dynamic analysis is $\mathrm{V}_{\mathrm{t}}$.

Table 3. Comparison of the records in set and the records selected by DB method.

\begin{tabular}{|c|c|c|c|c|c|c|c|c|c|c|}
\hline \multirow{4}{*}{ Structures } & \multirow{4}{*}{$\mathbf{V}_{\mathrm{s}} \mathbf{k N}$} & \multicolumn{3}{|c|}{ Alternative set } & \multicolumn{6}{|c|}{ Selected by DB method (proposed by Yang et al.) } \\
\hline & & \multirow{2}{*}{\multicolumn{2}{|c|}{$\begin{array}{l}\text { Time-history } \\
\text { analysis }\end{array}$}} & \multirow{3}{*}{$\mathbf{V}_{\mathrm{t}} / \mathbf{V}_{\mathrm{s}}$} & \multicolumn{4}{|c|}{ Time-history analysis } & \multirow{3}{*}{$\mathbf{V}_{\mathrm{t}} \mathbf{k N}$} & \multirow{3}{*}{$\mathbf{V}_{\mathrm{t}} / \mathbf{V}_{\mathrm{s}}$} \\
\hline & & & & & \multicolumn{3}{|c|}{ Period range } & \multirow{2}{*}{$\begin{array}{c}\begin{array}{c}\text { Platform } \\
\text { range }\end{array} \\
\delta\end{array}$} & & \\
\hline & & $\begin{array}{l}\text { Record } \\
\text { number }\end{array}$ & $\mathbf{V}_{\mathrm{t}} \mathbf{k N}$ & & $\begin{array}{l}\text { Period } \\
\text { segment }\end{array}$ & $\begin{array}{c}\text { Ground } \\
\text { motion } \\
\text { number }\end{array}$ & $\delta$ & & & \\
\hline \multirow{7}{*}{ Structure 1} & \multirow{7}{*}{994.30} & 746 & 910.25 & $91.55 \%$ & \multirow{7}{*}{$\begin{array}{l}{[0.39 \mathrm{~s}} \\
1.09 \mathrm{~s}]\end{array}$} & $\mathrm{N}-216$ & $1.52 \%$ & $0.72 \%$ & 1253.24 & $126.04 \%$ \\
\hline & & 1380 & 1123.05 & $112.95 \%$ & & B-8 & $1.85 \%$ & $7.23 \%$ & 747.81 & $75.21 \%$ \\
\hline & & 3752 & 1190.05 & $119.69 \%$ & & $* \mathrm{~N}-140$ & $3.18 \%$ & $6.94 \%$ & 558.25 & $56.15 \%$ \\
\hline & & 945 & 700.80 & $70.48 \%$ & & $\mathrm{~N}-204$ & $8.53 \%$ & $1.10 \%$ & 1449.81 & $145.81 \%$ \\
\hline & & 5808 & 678.32 & $68.22 \%$ & & N-184 & $8.93 \%$ & $7.96 \%$ & 1015.71 & $102.15 \%$ \\
\hline & & 1290 & 809.94 & $81.46 \%$ & & $\mathrm{~N}-244$ & $9.23 \%$ & $0.95 \%$ & 1028.05 & $103.39 \%$ \\
\hline & & Mean & 902.07 & $90.73 \%$ & & Mean & & & 1008.81 & $101.46 \%$ \\
\hline \multirow{8}{*}{ Structure 2} & \multirow{8}{*}{1709.23} & 1190 & 1983.20 & $116.03 \%$ & \multirow{8}{*}{$\begin{array}{l}{[0.82 \mathrm{~s}} \\
1.52 \mathrm{~s}]\end{array}$} & $\mathrm{N}-140$ & $4.85 \%$ & $6.94 \%$ & 1390.36 & $81.34 \%$ \\
\hline & & 4183 & 2261.57 & $132.32 \%$ & & $\mathrm{~N}-256$ & $5.32 \%$ & $7.69 \%$ & 1845.75 & $107.99 \%$ \\
\hline & & 1274 & 1657.67 & $96.98 \%$ & & N-68 & $9.33 \%$ & $8.94 \%$ & 1346.08 & $78.75 \%$ \\
\hline & & 945 & 2144.75 & $125.48 \%$ & & $\mathrm{~N}-92$ & $9.98 \%$ & $1.93 \%$ & 1215.88 & $71.14 \%$ \\
\hline & & 6896 & 1917.24 & $112.17 \%$ & & & & & & \\
\hline & & 1276 & 2158.05 & $126.26 \%$ & & & & & & \\
\hline & & 5805 & 1153.42 & $67.48 \%$ & & & & & & \\
\hline & & Mean & 1896.56 & $110.96 \%$ & & Mean & & & 1449.52 & $84.81 \%$ \\
\hline \multirow{6}{*}{ Structure 3} & \multirow{6}{*}{17511.63} & 1813 & 26193.39 & $149.58 \%$ & \multirow{6}{*}{$\begin{array}{l}{[3.45 \mathrm{~s}} \\
4.15 \mathrm{~s}]\end{array}$} & & & & & \\
\hline & & 746 & 24109.82 & $137.68 \%$ & & & & & & \\
\hline & & 1291 & 17209.56 & $98.28 \%$ & & & & & & \\
\hline & & 1581 & 28088.31 & $160.40 \%$ & & & & & & \\
\hline & & 6896 & 18065.32 & $103.16 \%$ & & & & & & \\
\hline & & Mean & 22733.28 & $129.82 \%$ & & & & & & \\
\hline \multirow{3}{*}{ Structure 4} & \multirow{3}{*}{21371.47} & 6988 & 16514.79 & $77.27 \%$ & \multirow{3}{*}{$\begin{array}{l}{[4.45 \mathrm{~s}} \\
5.15 \mathrm{~s}]\end{array}$} & & & & & \\
\hline & & 6896 & 23107.88 & $108.12 \%$ & & & & & & \\
\hline & & Mean & 19811.34 & $92.70 \%$ & & & & & & \\
\hline
\end{tabular}


From the calculating results, twenty-nine ground motion records from the set were selected for the four structures; furthermore, all the results meet the requirements of base shear statistical rule. Six and four records were selected, respectively, for structure 1 and structure 2 with shorter structure periods by the DB method, and even structure 3 and structure 4 with longer structure periods failed to select records by the DB method. If requirements of base shear statistical rule are added, only four and five records for structure 1 and structure 2 can be qualified separately (with * part of Table 3 is failure in meeting the requirements of base shear statistical law); thus, no record is qualified for structure 3 and structure 4 . It shows that the records are selected from the set with a wide range of application, which are beneficial not only for shorter period structures, but also for longer period structures, especially since the DB method failed to do so in long period ranges. Furthermore, all records can meet the base shear requirement, which demonstrates high availability of records in the set.

\section{CONCLUSIONS}

The SDB method was set forth in this paper, which considered the higher modes to select ground motion records. And the record set was constructed by the SDB method based on response spectrum. Furthermore, the records in the set were put into structures to do time-history dynamic analysis. The conclusions are as follows:

(1) The modal participating mass ratio $\eta_{i}$ was used as the weight coefficient to consider the higher modes, which represents the contribution of the ith mode to the seismic response of the structure. The sectionalized-dual-band method considering the influence of higher modes to select ground motion records was proposed. And the period range was determined by the weight coefficient of multiple frequency bands composed of several vibration periods of the structures.

(2) Ground motion records were initially selected by the PEER and then selected by the SDB method to construct the record set, observing the principle of consistency between record spectrum and design spectrum. Furthermore, the record sets with various fortification intensities and site characteristic periods can compose the ground motion record database. Hence, the records in the database can be used directly as the basic period of structure is determined, which can avoid tedious work for reselecting records due to various different structures. To omit the complicated process and save time, facilities will be offered for records selection in practical engineering.

(3) The time-history dynamic analysis of engineering structures verified the effectiveness of records in the set, under the evaluation principle of base shear according to the Chinese seismic design code. And the amount of records (selected by the SDB method) in the set was proved to be more adequate than that selected randomly by the DB method. Especially, for long period structures, the record set can offer qualified records, but the dual-band method cannot.

\section{ACKNOWLEDGMENT}

Thanks are due to the ground motion records data provided by PEER.

\section{REFERENCES}

ATC-63, 2009. Quantification of Building Seismic Performance Factors. Applied Technology Council, Washington D C.

ASCE/SEI 7-16, 2017. Minimum Design Loads for Buildings and Other Structures. American Society of Civil Engineers, Reston, Virginia.

Baker, J.W. 2010. Conditional Mean Spectrum: Tool for Ground-motion Selection. J. Journal of Structural Engineering, 137(3): 322-331.

Bommer, J. \& Acevedo, A. 2004. The Use of Real Earthquake Accelerograms as Input to Dynamic Analysis. J. Journal of Earthquake Engineering, 8(1): 43-91.

Bradley, B.A. 2010. A Generalized Conditional Intensity Measure Approach and Holistic Ground-motion Selection. J. Earthquake Engineering \& Structural Dynamics, 39(12): 1321-1342. 
California Geological Survey-Strong Motion Instrumentation Program (CGS-SMIP) and the Pacific Earthquake Engineering Research Center-Lifelines Program (PEER-LL), 2010. Technical Report for the PEER Ground Motion Database Web Application, Available at http://peer. berkeley. Edu/ peer. ground motion database/ site/ documentation

Carlson, C., Zekkos, D. \& Athanasopoulos-Zekkos, A. 2016. Predictive Equations to Quantify the Impact of Spectral Matching on Ground Motion Characteristics. J. Earthquake Spectra, 32(1): 125-142.

GB50011-2010 (2016 Version), 2016. Chinese code for seismic design of buildings. Architecture \& Building Press, Beijing, China.

Haselton, C.B. 2009. Evaluation of Ground Motion Selection and Modification Methods: Predicting Median Inter-story Drift Response of Building. PEER Report, Pacific Earthquake Engineering Research Center, University of California, Berkeley.

Hashash, Y.M.A., Abrahamson, N.A., Olson, S.M., Hague, S. \& Kim, B. 2015. Conditional Mean Spectra in Site-specific Seismic Hazard Evaluation for a Major River Crossing in the Central United States. J. Earthquake Spectra, 31(1): 47-69.

Hou, H. \& Liu, W. 2019. A Constructing Method for Ground Motion Alternative Database Based on Response Spectrum. J. Journal of Vibration and Shock, 38(9): 44-52.

Ji, K., Bouaanani, N., Wen, R. \& Ren, Y. 2017. Correlation of Spectral Accelerations for Earthquakes in China. J. Bulletin of the Seismological Society of America, 107(3): 1213-1226.

Katsanos, E.I., Sextos, A.G. \& Manolis, G.D. 2010. Selection of Earthquake Ground Motion Records: A State of the Art Review from a Structural Engineering Perspective. J. Soil Dynamics and Earthquake Engineering, 30(4): 157-169.

Lu, D., Liu, T. \& Li, S. 2018. Investigation of Target Spectrum and Amplitude Scaling Methods on Selection of Ground Motions. J. Earthquake Engineering and Engineering Vibration, 38(4): 21-28.

Stewart, J.P., Chious, S.J. \& Bray, J.D. 2002. Ground Motion Evaluation Procedures for Performance-based Design. J. Soil Dynamics \& Earthquake Engineering, 22(9): 765-772.

Wang, G., Youngs, R., Power, M. \& Li, Z. 2015. Design ground motion library: an interactive tool for selecting earthquake ground motions. J. Earthquake Spectra, 31(2): 617-635.

Yang, P., Li, Y.M. \& Lai, M. 2000. A New Method for Selecting Inputting Waves for Time-history Analysis. J. China Civil Engineering Journal, 33(6): 34-37.

Zhou, Y. \& Tang, S. 2014. A Method of Engineering Ground Motion Selection Considering Higher Modes. J. Earthquake Engineering and Engineering Dynamics, 34(8): 69-75. 